\title{
THE / CHING OR "BOOK OF CHANGES": A CHINESE SPACE-TIME MODEL AND A PHILOSOPHY ÖF DIVINATION
}

\author{
Benjamin B. Olshin, PhD \\ (Assistant Professor) \\ Department of Philosophy, History, and \\ History of Science Liberal Arts Division \\ University of the Arts \\ Terra Building, 211 South Broad Street \\ Philadelphia, PA 19102 USA. \\ E-mail: bolshin@uarts.edu
}

\section{Introduction}

Although often written about, studied, cited, and referred to casually, the I Ching or "Book of Changes" as it is commonly known in English is not well understood in the context of Chinese metaphysics. In this paper, we wish to set the IChing in the context of a particular space-time model of the Chinese. By "space-time", I mean the relationship between events in time, and locations of those events in physical space. I will also look at this classic work in the context of what is poorly rendered into English as "divination". Indeed, the I Ching is often referred to as a book of divination or fortune-telling, when it is clear that it is not this at all, but rather a kind of "mental map" designed to guide the reader (or rather, user) through this Chinese space-time environment.

The idea of divination - of perceiving what is going to happen - runs against our modern conceptions of space-time. When I toss a coin into the air, that tossing is a distinct event in space and time, and is not connected with any other event, except the interaction with my hand and the surrounding air. Which side the coin lands on is not something I can readily determine. The result is governed by chance, although theoretically I could carry out a vast number of calculations of air currents, molecular movements, and so on, and 
from these figure out how the coin will land. Our primary approach to such chance events as a coin toss is through the utilization of complex statistical systems and laws of probability; these comprise our contemporary tools for examining events that we cannot determine with certainty.

Our modern statistical notions are based on a very particular view of the universe. This view is that the future has yet to take place and that right now we are at the forefront of time and events. We are moving at the head of a long time-line, stretching back into the past. To speak of future events is to speak of things that do not yet exist, and, in fact, cannot even be imagined.

However, there are other conceptions of time and probability. For our purposes here, we will focus on the conception known as the "block universe", where everything that has and will take place in fact all exists together, co-temporaneously. In this model, we feel that we experience events in a linear fashion, but in actuality, all the events - past and future - are all fixed already "out there". in the space-time. ${ }^{1}$

We must also consider that our own everyday view of our relationship to the universe as a whole is somewhat contradictory. On the one hand, we acknowledge that all events and actions are interrelated. The common adage is that the flap of a butterfly's wings in a Borneo jungle can lead to a thunderstorm in Paris. If we do something, take an action of some kind, we can trace a series of consequences from that action. However, for the most part, in our modern thinking, we are not really related to the universe at large. Our actions are independent, and affect and are affected by only those things in our immediate surroundings.

The ancient Chinese conception was much different, and involved a particular view of the universe. A modern commentator writes: 
Everything that happens happens within time. We like to think that time stretches illimitably forward into the future and illimitably back into the past while we exist on a hairline of time that separates the future from the past, the hairline we call, "now". Quite the reverse is true; all there is and was and ever can be is an endless now, within which change occurs. ${ }^{2}$

This "endless now" is another way of describing what we have called above the "block universe". Moreover, the fact that the space-time universe has this form - at least according to the Chinese model - means that our knowledge of it can be quite specific:

Within that endless now, we are eternal, as is everything else...

Because we are a part of the universe, and because time is a living, breathing entity that contains consciousness - may indeed be consciousness of the universe, permeating everything, including ourselves - we can know everything the universe knows; all we need is a key to unlock the fount of sublime wisdom and complete information. That there is a key is unquestionable; every time a new idea seems to arise spontaneously, we have used the key. Egotistically, we like to think that we created the idea, but actually, what we did was no less noteworthy: we channelled the idea from the source, we used the key. ${ }^{3}$

This leaves us with a very particular definition for "divination":

That the key exists within each of us is the premise of all divination. Divination surmises that there is a part of us that is at one with everything, including time, and therefore knows what everything knows. The English root word of divination is divine. The Latin root word is divinus, meaning a deity... ${ }^{4}$

In short, the Chinese philosophy of our relationship to the universe as exhibited in the I Ching is as follows: 
- All events and situations, and the permutations of those events and situations, exist simultaneously.

- We are each connected, inextricably, to the universe, in all respects; this is what is known as "correlative cosmology". ${ }^{5}$

- We are not typically conscious of this connection, but we can perceive it if we use the appropriate tools and methods.

- If we become conscious of this connection, we can "foresee what will happen", or, to put it in a way more in line with Chinese thinking, we can perceive the "correct" path of the "many" that exist simultaneously.

These points illustrate the fact that Chinese divination is not all about "reading the future" in some sense of seeing "up the line" into the future: rather, it is reading a map that is already laid out. We will investigate this model here.

\section{The / Ching or "Book of Changes"}

The classic book for Chinese divination is called the I Ching. The title literally means "Changes Book", or, more commonly, "Book of Changes". Its exact authorship is uncertain; the original text is very old, and was added to over time. Speaking in very rough terms, the work is some 3000 years old, with modifications, revisions, and interpretative addendum as part of that long history. Richard Wilhelm, a translator of the I Ching, describes the development of the form of Chinese divination found in this text:

At the outset, the "Book of Changes" was a collection of linear signs to be used as oracles. In antiquity, oracles were everywhere in use; the oldest among them confined themselves to the answers yes and no. This type of pronouncement is likewise the basis of the "Book of Changes." "Yes" was indicated by a simple unbroken line $(-)$, and "No" by a broken line $(-\longrightarrow)^{6}$ 
Wilhelm continues:

However, the need for greater differentiation seems to have been felt at an early date, and the single lines were combined in pairs.

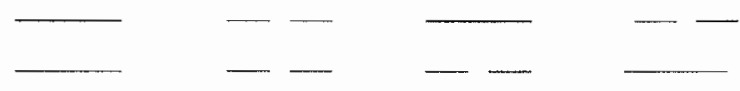

To each of these combinations a third line was then added. In this way, the eight trigrams came into being. These eight trigrams were conceived as images of all that happens in heaven and on earth. At the same time, they were held to be in a state of continual transition from one phenomenon to another is continually taking place in the physical world. Here we have the fundamental concept of the Book of Changes. The eight trigrams are symbols standing for changing transitional states; they are images that are constantly undergoing change. Attention centres not on things in their state of being - as is chiefly the case in the Occident - but upon their movements in change. The eight trigrams there are not representations of things as such but of their tendencies in movement. ${ }^{1}$

The eight trigrams were given certain meanings, and they came to be associated with various aspects of nature (see Fig.1). This simple scheme itself shows the philosophical concept of the interconnectedness of all events, attributes, images (i.e., aspects of the environment), and relationships in the space-time model of the I Ching.

Notice how the trigrams are each related to some characteristic or descriptive quality: So that there might be even greater descriptive power in this system, the eight trigrams were combined with one another. This resulted in what are called in English "hexagrams"; there were 64 in total. A user of the I Ching could come up with a 
hexagram through a method involving the toss of yarrow stalks (or, sometimes, coins). Each of the 64 hexagrams has an explanatory text, which, through interpretation, addresses the question of the user. $^{2}$

These questions usually take the form of decision-making issues; for example, a modern user of the I Ching might ask, "Should I accept this new job offer?" More precisely, the user would ask, "What are the existing factors (in the great universal now) that I should consider when deciding whether or not to accept this new job offer?" Then the user of the $I$ Ching would cast the yarrow stalks or toss coins, and come up with one of the 64 hexagrams. Each hexagram and its explanatory text provide the user an "answer" to the questioner in the sense that the relevant parameters and factors of the question are articulated - although in very obscure language. For example, a user might, in answer to the job question above, get the hexagram Kun (䖯), translated as "The receptive". The text (in Wilhelm's translation) for this hexagram runs as follows:

THE RECEPTIVE brings about sublime success,

Furthering through the perseverance of a mare.

If the superior man undertakes something and tries to lead,

He goes astray;

But if he follows, he finds guidance.

It is favourable to find friends in the west and south,

To forego friends in the east and north.

Quiet perseverance brings good fortune.

How does this serve as an "answer" to the user of the I Ching, the questioner? Well, clearly it is a matter of interpretation. Nevertheless, in this space-time model, the fact that it is the hexagram that came up in reply to the questions is not a chance event. For it is this hexagram that provides the absolutely appropriate description of the relevant factors in relation to your question, at the precise nexus of space and time in which you cast the yarrow stalks. In other 
words, there could have been no other hexagram for that moment, and hence there is no chance involved.

So, why the obscure nature of the text itself? There is the inherent vagueness of the Chinese language itself, and the fact that oracular language is vague (if, in fact, the $I$ Ching has its origins in oracular texts). But to keep with our main theme of the I Ching as a space-time model, let us consider that it, like the Tao, is an attempt to be comprehensive of all existence. Even to attempt that with words means to be vague; to try to apply the severely limited tool of language to something as mysterious and transcendent as the universe and its elements means that we will come up short. The comprehensive space-time, the complex matrices of existing forces, natural events, and human actions, can only be described through broad strokes of knowledge. But since our human intellect, according to this model, is also part of this vast space-time, we have the capacity to "get it right" in our interpretation of the text. The meaning is all there in the hexagram, even in its vagueness and obscurity, if we apply our full intellect and interpretive capacity.

But to return to the divinatory method: we see that there is not simply an outside observer or questioner inquiring of a book in search of an answer about the future. Rather, the questioner, the book, the yarrow stalks, the physical setting, and the exact moment in time are all components in the casting and interpretive process. In a sense, the action of divination is inside space and time, and is a quest for clarity, not a quest to see something unknown or hidden. 


\begin{tabular}{|c|c|c|c|c|}
\hline Trigram & Name & Attribute & Image & Family Relationship \\
\hline Qian & the creative & strong & heaven & Father \\
\hline$-\ldots i m$ & the receptive & devoted & Earth & Mother \\
\hline __ Z Zhen & the arising & inciting & thunder & first son \\
\hline$\ldots_{-}^{K a n}$ & the abysmal & dangerous & Water & second son \\
\hline${ }_{-}{ }^{G e n}$ & keeping still & resting & mountain & third son \\
\hline${ }_{-}{ }_{-}^{X u n}$ & the gentle & penetrating & wind / wood & first daughter \\
\hline${ }_{-}{ }^{L i}$ & the clinging & light-giving & fire & second daughter \\
\hline${ }_{-}{ }^{D u i}$ & the joyous & joyful & lake & third daughter \\
\hline
\end{tabular}


The basic physical process in the divinatory method of the I Ching is to draw up a question, cast about with yarrow stalks or coins to come up with a series of broken and/or unbroken lines that form the hexagram, and then read the corresponding text for that particular hexagram. Through a somewhat complex system, each hexagram came to signify a combination of forces, situations, changes, etc. A modern Chinese commentator who worked in the field of statistics for many years, Dr. Hsing-Chu Hsu, a statistician, has noted that this system is much more mathematical than it appears. ${ }^{1}$ When we speak of the IChing, we often look at it simply as "fortune telling", as noted above. But Hsu has pointed out that the I Ching is in some sense a statistical model of the universe, and he notes that this is an aspect even more visible in other forms of Chinese divination, such as that known by the peculiar name, "Purple Astrology" (in Chinese, 紫微斗数, zi wei dou shu).

The use of lines as a means of prognostication goes far back in Chinese history: in the Lungshan period, some 4000 years ago, the shoulder-blade bone of cows were used for divination. The bone was held over a fire, while the diviner asked a question; the heat produced cracks in the bone, and a skilled interpreter deduced the answer to the question by examining the position and shape of the cracks. This practice later became more elaborate and ritualized. The question itself was inscribed on the shoulder-blade bone. A heated bronze poker was applied to a certain area of the bone, and again the cracks were examined. Examples of these "oracle bones" still survive, and they can be seen at the National Palace Museum in Taiwan. Another method involved the use of specially prepared tortoise shells, which were heated to produce cracks. The tortoise was used because it was considered a symbol of stability and longevity. Its shell was considered one of the sacred items ordained by heaven for use in oracles.

Indeed, according to ancient mystical tradition, the eight basic trigrams of the IChing were first discovered on the back of a tortoise. The finding of these trigrams is attributed to a certain $\mathrm{Fu} \mathrm{Xi}$, the 
first (and probably mythical) emperor of the Chinese, who is reputed to have lived over 4500 years ago. One of the commentaries on the I Ching describes that discovery:

When in early antiquity Pao Hsi [another name for Fu Xi] ruled the world, he looked upward and contemplated the images in the heavens; he looked downward and contemplated the patterns on earth. He contemplated the markings of birds and beasts and the adaptations to the regions. He proceeded directly from himself and indirectly from objects. Thus he invented the eight trigrams in order to enter into connection with the virtues of the light of the gods and to regulate the conditions of all beings. ${ }^{1}$

Note here the idea of "as above, so below", the "macrocosm in microcosm" concept so very common to many systems of belief, such as the Jewish Cabbalists. This is more or less the same as the idea of "correlative cosmology" mentioned earlier.

As noted above, the eight trigrams were used in an early form of divination, and are still today often depicted in Chinese art and design. They are often shown encircling the interlocking Yin and Yang symbols. The dark area, Yin, contains a white dot, and the light area, Yang, contains a black dot. This symbolizes the idea that even in the purest state, each side contains the seed of the other, or, change operates even as this most fundamental level.

first (and probably mythical) emperor of the Chinese, who is reputed to have lived over 4500 years ago. One of the commentaries on the I Ching describes that discovery:

When in early antiquity Pao Hsi [another name for Fu Xi] ruled the world, he looked upward and contemplated the images in the heavens; he looked downward and contemplated the patterns on earth. He contemplated the markings of birds and beasts 
and the adaptations to the regions. He proceeded directly from himself and indirectly from objects. Thus he invented the eight trigrams in order to enter into connection with the virtues of the light of the gods and to regulate the conditions of all beings. ${ }^{1}$

Note here the idea of "as above, so below", the "macrocosm in microcosm" concept so very common to many systems of belief, such as the Jewish Cabbalists. This is more or less the same as the idea of "correlative cosmology" mentioned earlier.

As noted above, the eight trigrams were used in an early form of divination, and are still today often depicted in Chinese art and design. They are often shown encircling the interlocking Yin and Yang symbols. The dark area, Yin, contains a white dot, and the light area, Yang, contains a black dot. This symbolizes the idea that even in the purest state, each side contains the seed of the other, or, change operates even as this most fundamental level.

Around 1143 BC., the last Shang Dynasty emperor, Chou Hsin, imprisoned the feudal lord, Wen, in the province of Chou, in Western China. Wen was very popular with the people, and this incurred the emperor's wrath. While in prison, Wen studied the eight trigrams. Combining them, he arrived at the 64 six-line hexagrams. He then went on to name each, and added an explanatory text for each as well. 


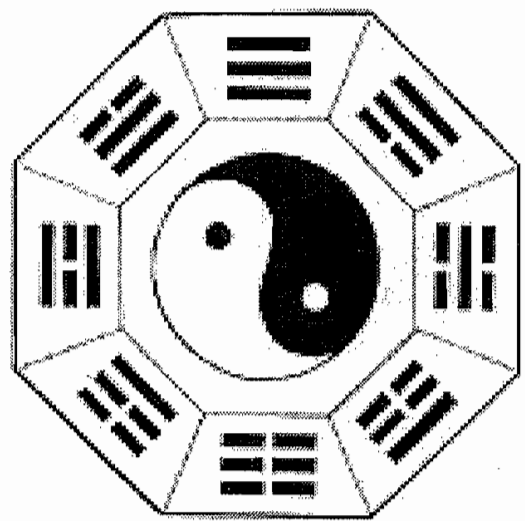

Figure 2. The eight trigrams, or ba gua, as they are often portrayed, in an octagonal format with the yin-yang symbol at centre.

The forces of the province of Chou rebelled against the emperor soon after this, and Chou Hsin was overthrown; the Shang dynasty was ended. A series of battles ensued, with the final victory being achieved by Wen's son, Tan, the Duke of Chou, who founded the Chou dynasty. Forty years after Wen had worked out the hexagrams, the Duke expanded on his father's work on them. He added a series of interpretations. This work, with the 64 hexagrams and accompanying text by Wen, plus the added interpretations of the Duke of Chou, became widely known throughout the Chou Empire under the title of Chou I ("The Changes of Chou").

In the early part of the $5^{\text {th }}$ century BC., Confucius studied the Chou I, and he may have written one of the commentaries that are often attributed to him. His students and others composed further commentaries, until they comprised a work as large as the original text of Wen and his son. The oracle became officially recognized as one of the five Confucian classics, and gained the name I Ching, or "Book of Changes".

The I Ching escaped the fate of the other classic works at the time of the famous burning of books under the Emperor Ch' in Shih Huang Ti, in $213 \mathrm{BC}$. The I Ching was also adopted for a time by a 
school of magicians of the Chin and Han dynasties; these were practitioners of a type of Taoist occultism. Later, a scholar named Wang $\mathrm{Pi}$, in the third century AD., wrote a treatise on the I Ching, and this is the version that is essentially the one now in use.

\section{The / Ching as Space-Time Model}

The I Ching can be seen as a model of space-time that emphasizes complete connectedness, and thus a way of looking at events in a very particular way. The famous psychologist Carl Jung wrote:

The Chinese mind, as I see it at work in the I Ching, seems to be exclusively preoccupied with the chance aspect of events. What we call coincidence seems to be the chief concern of this peculiar mind, and what we worship as causality passes almost unnoticed...

The manner in which the I Ching tends to look upon reality seems to disfavour our causalistic procedures. The moment under actual observation appears to the ancient Chinese view more of a chance hit than a clearly defined result of concurring causal chain processes. The matter of interest seems to be the configuration formed by chance events in the moment of observation, and not at all the hypothetical reasons that seemingly account for the coincidence. While the Western mind carefully sifts, weighs, selects, classifies, isolates, the Chinese picture of the moment encompasses everything down to the minutest nonsensical detail, because all of the ingredients make up the observed moment.

Thus it happens that when one throws the three coins, or counts the forty-nine yarrow stalks [two ways of using the IChing], these chance details enter into the picture of the moment of observation and form a part of it -- a part that is insignificant to us, yet most meaningful to the Chinese mind. ${ }^{1}$ 
Jung goes on to compare the Western causal view and the Chinese "synchronistic" view as follows:

The causal point of view tells us a dramatic story about how $D$ came into existence: it took its origin from $C$, which existed before $D$, and $C$ in its turn had a father, $B$, etc. The synchronistic view on the other hand tries to produce an equally meaningful picture of coincidence. How does it happen that $A^{\prime}, B^{\prime}, C^{\prime}, D^{\prime}$, etc., all appear in the same moment and in the same place? ${ }^{2}$

The IChing may be seen to represent a kind of statistical description of the universe. For the Chinese, the moment, the precise time, place, and circumstances when the $I$ Ching is being consulted, represents a given statistical state. It is interesting to note that Gottfried Wilhelm von Leibniz (1646-1716), the famed philosopher, was familiar with the I Ching. Leibniz contemplated the idea that the order of the universe is reflected in its parts - and, as we have already mentioned, this idea is a fairly common one in various systems of beliefs. Joachim Bouvet, a Jesuit who had lived in China, wrote Leibniz a letter in which he outlined the structure of the I Ching. Leibniz saw in this work a strong connection to his own general idea of dualities, and more particularly, the binary code. ${ }^{3}$

Despite the apparently "chance" nature of the casting of the yarrow stalks or tossing coins, we should not believe that IChing is simply a Chinese portrayal of a universe governed by randomness. On the contrary - "chance" events are simply manifestations of an eternal, underlying principle:

The whole text of the IChing presupposes a strong conviction of the existence of an order in the universe although such an order may be very different from the one prevailing in traditional Western thought. ${ }^{4}$ 
The question, then, how we might carry out this "divining", if we wish to use that word, of this order.

\section{A Philosophy of Divination}

The I Ching presents us with a model of the universe where all events - including the apparently meaningless or casual toss of yarrow stalks - are not only connected, but also connected in a way that can be interpreted. This is a key point, but one that can be glossed over too easily with the response that, "of course, all events are related". What is different here is the fact that the "small event" - that is, the result of the toss of the yarrow stalks - is a direct reflection of the space-time moment of the questioner or user of the I Ching, and therefore has enormous interpretative power. As one writer on the $I$ Ching as a statistical artefact has pointed out, "It can be argued...that the outcome of any true divination is not dependent on chance - that external factors are operating which ensure that the result is what "ought to be". .5

The inter-connectedness of events allows them to be "predicted" or understood. But the nature of this inter-connectedness is not quite clear, although Taoism points one way. In the most basic terms, one might say that in the ancient Chinese perspective, since the Tao (literally, "the Way") is root causation and substance of all existence, all material things and events are manifestations of it, and thus are related. The problematic nature of defining this relationship is illustrated in the various interpretations of the I Ching through history. We can mention here as an example one use of the text where the "I Ching is no longer... used to foil fate but is understood as the exposition of a great cosmology." In this usage, there is a "latent power" in the universe "which becomes manifest in application", a universe which is "unfolding from the No-thing into an extremely variegated Universe". "The "No-thing" refers to a Taoist concept of the universe, where, again, the Tao is a kind of substrate of all things.

Given this context, one does not strive to predict the future 
in the common sense in which that expression is used, but rather to understand the unfolding of events. Moreover, in its connection with Taoism, we can see that $I$ Ching is a guide to conducting oneself in harmony with the universe:

All things derive their destination from the Tao, the No-thing, which is the substance of the Universe. If you wish to arrive whither you are destined to go, you must not stray from your source. If you do not want to stray from your source, your life must be no more than a manifestation of the No-thing, which means a manifestation of the Whole of the Original Substance. $^{8}$

Our "philosophy of divination" in a sense must be redefined - we are talking more about a "philosophy of prognostication", perhaps. "Prognostication" is an interesting word, since it directly incorporates gnosis, that is, knowledge. Thus, we are talking about knowledge of the future, but in the same sense that we have knowledge in any situation. In the everyday world, we use our senses, combined with intellect, in our efforts to make rational decisions. We try to gather as much knowledge as possible. In the slightly more mystical realm of the $I$ Ching, the same operative principles are at work: the hexagrams are used to assemble information or insight for sound decision-making. One writer describes these divinatory methods succinctly as " $[\mathrm{m}]$ ystical systems involving permutational procedures that purport to reveal a body of hermetic knowledge or that lead to a revelatory exhaustion of all possibilities..."

We can further define the IChing text not as a book for telling us about the future per se, but something else. There is indeed the conception that there is a future "out there". But reading that future is not the objective of the user of the I Ching: 
Rather than a manual for predicting the future, it is a text meant to elucidate the necessities and potential of the present, to tell one what to do, instead of what is going to happen. It is consulted by throwing coins, or by dividing bundles of yarrow stalks at random - in other words, by means of "chance" in which the reader... is involved. ${ }^{10}$

Nevertheless, as outlined earlier, this is not simply a random event:

The fall of the coins or stalks reflects the configuration of the universe, the effects of its innumerable variable pressures at any given moment; and this method of consulting the oracle clearly presupposes a universe in which all events are interconnected and no phenomenon is insignificant."

To be even more precise, there is, in a sense, no future, especially since we are dealing with what is essentially a "block model" of the universe. Since this is the case, the I Ching is simply a diagram of things as they are, in all states, both manifest and yet to be manifested. The author of an article on statistical methodology of the I Ching puts it as follows:

It can be argued... that the outcome of any true divination is not dependent upon chance - that external factors are operating which ensure that the result is what it "ought to be"... Thus at any given moment, the fall of the coins or the outcome of the division of the stalks is what is necessarily must be, insofar as it is an essential part of that moment and hence possess the particular quality peculiar to it. ${ }^{12}$

Thus, the whole process of divination, or prognostication, is a threestep "reading" of a moment. These are (a) the performing of an action or "event" (the coin toss / yarrow stalk division) that has a 
correlative value with the universe as a whole; (b) the "reading" of that action (finding the corresponding hexagram); and (c) the interpretation of the reading in relation to the situation of the user of the I Ching. The process is one of gathering knowledge, as unclear as that knowledge might be to us. As such, we can speak of the "epistemological justifications for the use of the I Ching and similar systems of divination". ${ }^{13}$ Does the process of casting yarrow stalks and reading hexagrams to help us answer questions have any validity in terms of rational thinking? It has been said that the I Ching could be seen as a kind of statistical tool for decision-makers in early civilizations. ${ }^{14}$ But is it rational in any wider sense?

Our contemporary dismissive attitude towards divination is justified if we do not share the sort of unified, Taoist worldview that is described here as underlying the I Ching. Moreover, it can be argued that this traditional Chinese description of the universe too weakly explicates the connections between the apparently disparate events of the casting of the yarrow stalks and the object of inquiry - e.g., questions such as "Should I take this job?", "Should I marry this person?", and so on.

However, in that case the Westerner empiricist should be asked to articulate an alternative clearly. They might say that the result of the casting of the yarrow stalks or the coin toss is the result of the bouncing around of atoms, but this leaves us with two problems. First, even the most modern physics does not offer an adequate description of these "atoms", in the sense of material objects to which we can apply a faultless mathematical model of causality and interaction. How can we really talk about statistical models when we do not fully understand the materiality of what we are trying to model?

A more subtle problem with the Western view concerns the question of chance. The empiricist argues that the result of the division of the yarrow stalks or the toss of coins in the process of using the $I$ Ching is essentially a random event, one that depends on the various possible conditions or potentialities at the moment 
of the act of tossing or dividing. However, one could say that the Chinese view of a "block universe" is more correct, in the sense that there are, if we really think about, no such things as potentialities. All events simply are. I can say that I am not sure it will rain tomorrow or not; I can weigh the various factors (humidity, wind, and so on), and say that I am measuring the potential for rain. But the actual fact is that tomorrow it is or is not going to rain. The event will indeed be one way or the other. I cannot know it now, but it is going to be, and so in that sense already exists. The only potentiality is in my head, and is, we might say, completely imaginary - a collection of might be's and could be's. In the philosophical worldview of the I Ching presented here, the book does not discuss potentialities at all, but simply describes what is. 


\section{References and Notes}

1 For a clear overview of the "block universe" concept, see Paul J. Nahin, Time Machines: Time Travel in Physics, Metaphysics, and Science Fiction, $2^{\text {nd }}$ edition (New York: Springer Verlag, 1999) 150161.

2 Wu Wei, The I Ching (Los Angeles: Power Press, 1995) xiii-xiv. 3 Ibid.

4 Ibid.

5 For a discussion of this "correlative cosmology, see "Correlative Cosmology: The School of Yin and Yang" in Benjamin Schwartz, The World of Thought in Ancient China (Cambridge, MA: Harvard University Press, 1985). Also note pp.23-26 of Nathan Sivin, "Ruminations on the Tao and Its Disputers", Philosophy East and West, vol.42, no.1 (January 1992), 21-29, and p, 7 and n.12 on p.39 of Mary Evelyn Tucker, "Religious Dimensions of Confucianism: Cosmology and Cultivation", Philosophy East and West, vol.48, no.1 (January 1998), 5-45.

6 Richard Wilhelm, trans., The I Ching or Book of Changes, Princeton: Princeton University Press, 1977, xlix.

7 Ibid, xlix-1.

8 See Shih-Chuan Chen, "How to Form a Hexagram and Consult the I Ching", Journal of the American Oriental Society, 92.2 (1972), 237-249, and D. Robinson, "Divination in Ancient China", Applied Statistics, vol.4, no.3 (1975), 329-332 for an explanation and critique of the coin and yarrow stalk methods of using the IChing; also note Edward A. Hacker, "Brief Note on a Coin-Method Equivalent to the Yarrow-Stalk Method for Determining the Lines of a Hexagram in the I-Ching", Philosophy East and West, Vol.30, No.4 (October 1980), 535-536.

9 Dr. Hsing-Chu Hsu, personal communication, 2000.

${ }^{10}$ Richard Wilhelm, trans., The I Ching or Book of Changes, 328329.

"Ibid, xxii-xxiii. 
${ }^{12}$ Ibid, xxiv-xxv. For an interesting discussion of the Jungian idea of connectedness -- synchronicity - and the I Ching, see Wayne McEvilly, "Synchronicity and the I Ching", Philosophy East and West, vol.18, no.3 (July 1968), 137-149.

${ }^{13}$ For more on the relationship between Leibniz and the I Ching, see Daniel J. Cook and Henry Rosemont, Jr., "The Pre-Established Harmony between Leibniz and Chinese Thought", Journal of the History of Ideas, vol.42, no.2 (April-June 1981), 253-267; also note pp.585-589 of Schuyler Cammann, "Chinese Hexagrams, Trigrams, and the Binary System", Proceedings of the American Philosophical Society, vol.135, no.4 (December 1991), 576-589.

${ }^{14}$ See p.16 of Joseph S. Wu, "Causality: Confucianism and Pragmatism", Philosophy East and West, vol.25, no.1, The Problems of Causation: East and West (January 1975), 13-22.

${ }^{15}$ See p.332 of D. Robinson, "Divination in Ancient China".

${ }^{16}$ See p.124 of T'ang Yung-t'ung and Walter Liebenthal, "Wang Pi's New Interpretation of the I Ching and Lun-yu", Harvard Journal of Asiatic Studies, vol.10, no.2 (September 1947), 124-161.

${ }^{17}$ Ibid, p.124.

${ }^{18}$ Ibid, p.147.

${ }^{19}$ See p.20 of Janet Zweig, "Ars Combinatoria: Mystical Systems, Procedural Art, and the Computer", Art Journal, vol.56, no.3, Digital Reflections: The Dialogue of Art and Technology (Autumn 1997), 20-29.

${ }^{20}$ See p.21 of Raymond Nelson, "Mysticism and the Problems of Mystical Literature", Rocky Mountain Review, vol.30, no.1 (Winter 1976), 1-26.

${ }^{21}$ Ibid, p.21.

${ }^{22}$ D. Robinson, "Divination in Ancient China", 332.

${ }^{23}$ William Ophuls, "Rational Turn to an Oracle", Science, new series, vol.169, no.3949 (4 September 1970), 927-928.

${ }^{24}$ Note p.44 of Hirotugu Akaike, "[The Unity and Diversity of Probability]: Comment", Statistical Science, vol.5, no.4 (November 1990), 444-446. 


\section{Bibliography}

Akaike, Hirotugu, "[The Unity and Diversity of Probability]: Comment", Statistical Science, vol.5, no.4 (November 1990), 444-446.

Camman, Schuyler, "Chinese Hexagrams, Trigrams, and the Binary System", Proceedings of the American Philosophical Society, vol.135, no.4 (December 1991), 576-589.

Chen, Shih-Chuan, "How to Form a Hexagram and Consult the $I$ Ching", Journal of the American Oriental Society, 92.2 (1972), 237-249.

Cook, Daniel J. and Rosemont, Jr., Henry, "The Pre-Established Harmony between Leibniz and Chinese Thought", Journal of the History of Ideas, vol.42, no.2 (April-June 1981), 253267.

Hacker, Edward A., "Brief Note on a Coin-Method Equivalent to the Yarrow-Stalk Method for Determining the Lines of a Hexagram in the I-Ching", Philosophy East and West, Vol.30, No.4 (October 1980), 535-536.

McEvilly, Wayne, "Synchronicity and the I Ching", Philosophy East and West, vol.18, no.3 (July 1968), 137-149.

Nahin, Paul J., Time Machines: Time Travel in Physics, Metaphysics, and Science Fiction, $2^{\text {nd }}$ edition (New York: Springer Verlag, 1999).

Nelson, Raymond, "Mysticism and the Problems of Mystical Literature", Rocky Mountain Review, vol.30, no.1 (Winter 1976), 1-26.

Ophuls, William, "Rational Turn to an Oracle", Science, new series, vol.169, no.3949 (4 September 1970), 927-928.

Robinson, D., "Divination in Ancient China", Applied Statistics, vol.4, no.3 (1975), 329-332.

Schwartz, Benjamin, The World of Thought in Ancient China (Cambridge, MA: Harvard University Press, 1985).

Sivin, Nathan, "Ruminations on the Tao and Its Disputers", 
Philosophy East and West, vol.42, no.1 (January 1992), 21-29. T'ang, Yung-t'ung and Liebenthal, Walter, "Wang Pi's New Interpretation of the I Ching and Lun-yu", Harvard Journal of Asiatic Studies, vol.10, no.2 (September 1947), 124-161.

Tucker, Mary Evelyn Tucker, "Religious Dimensions of Confucianism: Cosmology and Cultivation", Philosophy East and West, vol.48, no.1 (January 1998), 5-45.

Wilhelm, Richard, trans., The I Ching or Book of Changes (Princeton: Princeton University Press, 1977).

Wei, Wu, The I Ching (Los Angeles: Power Press, 1995).

$\mathrm{Wu}$, Joseph S., "Causality: Confucianism and Pragmatism", Philosophy East and West, vol.25, no.1, The Problems of Causation: East and West (January 1975), 13-22.

Zweig, Janet, "Ars Combinatoria: Mystical Systems, Procedural Art, and the Computer", Art Journal, vol.56, no.3, Digital Reflections: The Dialogue of Art and Technology (Autumn 1997), 20-29. 